\title{
Respiration Monitoring System of Lung Phantom Using Magnetic Sensor
}

\author{
Imamul Muttakin $^{1}$, David Abraham ${ }^{2}$, Rocky Alfanz $^{3}$, Rohmadi $^{4}$ \\ ${ }_{1,2,3}$ University of Sultan Ageng Tirtayasa, Jl Jenderal Sudirman Km 3, Cilegon, Indonesia \\ ${ }^{4}$ C-Tech Labs Edwar Technology, Jl KH Hasyim Ashari No 79A Modern Business Park, Tangerang, Indonesia
}

\begin{tabular}{|c|c|}
\hline Article Info & ABSTRACT \\
\hline Article history: & Monitoring vital signs is substantial in healthcare to assist both diagnosis and \\
\hline Received Nov 12, 2017 & $\begin{array}{l}\text { treatment. This work proposes a means of telemonitoring system at initial } \\
\text { stage to observe respiratory pattern on lung phantom. Magnetic sensor }\end{array}$ \\
\hline Revised Jan 13, 2018 & module LDC1000 is used to read inductance value of conductive material in \\
\hline Accepted Jan 27, 2018 & $\begin{array}{l}\text { relation to distance variation. Therefore, respiration pattern can be observed. } \\
\text { In continuous mode, the inspiration inductance value is } 8 \mathrm{uH} \text {, while }\end{array}$ \\
\hline Keywords: & $\begin{array}{l}\text { expiration is } 17 \mathrm{uH} \text {, with stoppage is } 17 \mathrm{uH} \text {. For static measurement, the } \\
\text { inspiration inductance value is } 7.80 \mathrm{uH} \text {, while expiration is } 16.46 \mathrm{uH} \text { and }\end{array}$ \\
\hline LDC1000 & $\begin{array}{l}\text { stoppage is } 16.46 \mathrm{uH} \text {. Those values could be further referred for vital signs } \\
\text { telemonitoring system design based on contactless and portable devices. }\end{array}$ \\
\hline
\end{tabular}

Magnetic sensor

Respiration monitoring

Telemonitoring

Copyright $@ 2018$ Institute of Advanced Engineering and Science. All rights reserved.

\section{Corresponding Author:}

Imamul Muttakin,

University of Sultan Ageng Tirtayasa,

J1 Jenderal Sudirman Km 3, Cilegon, Indonesia.

Email: imamul@untirta.ac.id

\section{INTRODUCTION}

Vital signs monitoring is a way to detect system change of body. It is substantial in healthcare to assist both diagnosis and treatment. There are needs to conduct vital signs monitoring conveniently with fast but reliable measurement and less susceptible against object or environment generated artifact. This paves way for telemonitoring research which has been increasingly demanded in health technology [1].

The work in [2] described wearable respiratory rate monitoring. This study used piezo-resistive fabric sensor to measure respiration. Sensors are placed on clothes and the results will be read on the monitor via bluetooth. This tool is still less effective because a lot of interference from environment. Another wearable system was proposed in [3] to detect respiratory rate using an electromagnetic generator. The tool is placed outside the body on the chest and the results will be read on the monitor through cables connecting with the appliance. It is, however, less convenient and hindering user's mobility. Optical sensor and accelerometer placed on mouth was constructed as real-time wireless monitoring of respiratory diseases [4]. On the other hand, pressure sensitive array attached onto bed could be used as continuous monitoring system with limited flexibility [5]. A portable and low-cost wireless solution for respiration monitoring employs magnetic induction sensor that could be located on chest in contactless fashion [6].

In order to accommodate complexity of procedures and precision required in biomedical research, phantom shaped like human's body is designed [7]. Lung phantom resembling the original lung in terms of dimension and respiration pattern will be used. This research employs LDC1000 magnetic sensor as a contactless sensor, with short-range sensing, low-cost, and insensitivity towards environmental interference [8]. This work aims to leverage advancement in medical technology, particularly respiration monitoring, at initial stage. The system uses eddy current principle that can observe lung distance while inflate and deflate without being affected by object's movement. 


\section{RESPIRATION SYSTEM DESIGN}

Conductive material being moved towards magnetic field will invoke eddy current on its surface. This current imposes another field that can be detected as relative position of the target object against primary field's source (see Figure 1). Coil can be arranged as ac magnetic field exciter; and simultaneously employed as proximity sensor [9]. Magnetic sensor converts magnetic field to an equivalent electrical signal. Due to its accuracy and robustness, this sensor is implemented for detection of position [10].

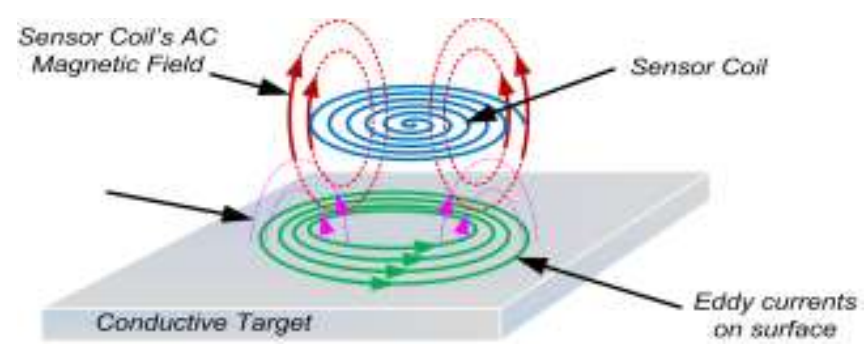

Figure 1. AC magnetic field interacts with conductor

Since biological tissue such as skin, particularly lung, has certain conductivity characteristics, its movement can be monitored by using electromagnetic methods. Respiration pattern is then obtained from the inferred proximity timing read by the sensor coil.

Hardware design comprises magnetic sensor and phantom (with pumping mechanism). Air circulation from oxygen tank is regulated by electronics controlled solenoid valve. It manages human normal respiration pattern and air volume in the lung phantom. Meanwhile, magnetic sensor will detect phantom's conductive surface and provide inductance value in accordance with proximity between the two. Those measured results are then acquired as raw data to be monitored and analyzed. In addition, there is graphical user interface (GUI) which comes with LDC1000 module as reference assessment. The instrument design is shown in Figure 2.

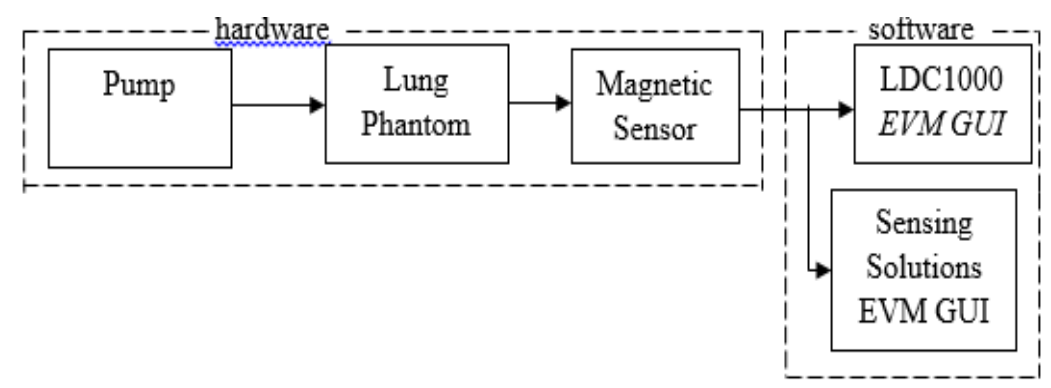

Figure 2. Respiration monitoring system block diagram

Lung phantom is fabricated resembling the real human lung (male) according to reference of pervious research with CT (Computed Tomography) images [11]. Table 1 shows detailed dimension.

Table 1. Lung Size by CT Images

\begin{tabular}{llccc}
\hline & Lung & Male & Female & Combined \\
\hline Peak to Peak & & $8.9 \pm 1.1(8.9) \mathrm{cm}$ & $7.7 \pm 0.9(7.6) \mathrm{cm}$ & $8.3 \pm 1.2(8.2) \mathrm{cm}$ \\
Height & Left & $21 \pm 2.1(21.8) \mathrm{cm}$ & $19 \pm 2.5(20.3) \mathrm{cm}$ & $19.8 \pm 2.6(20) \mathrm{cm}$ \\
& Right & $21 \pm 2.1(21.3) \mathrm{cm}$ & $19 \pm 2.5(19.3) \mathrm{cm}$ & $20.6 \pm 2.6(21) \mathrm{cm}$ \\
\multirow{3}{*}{ Max. Height } & Left & $28.2 \pm 2.2(27.4) \mathrm{cm}$ & $26 \pm 2.7(25.6) \mathrm{cm}$ & $26.1 \pm 2.6(26.5) \mathrm{cm}$ \\
& Right & $21 \pm 2.1(21.3) \mathrm{cm}$ & $26 \pm 2.7(26.3) \mathrm{cm}$ & $26.9 \pm 2.7(26.9) \mathrm{cm}$ \\
Width & Left & $12.3 \pm 1.1(10.6) \mathrm{cm}$ & $11.1 \pm 1(9.7) \mathrm{cm}$ & $10 \pm 1(10) \mathrm{cm}$ \\
& Right & $12.3 \pm 1.1(12.3) \mathrm{cm}$ & $11.1 \pm 1(11.2) \mathrm{cm}$ & $11.6 \pm 1.2(11.4) \mathrm{cm}$ \\
Depth & Left & $18 \pm 1.5(18.4) \mathrm{cm}$ & $16.2 \pm 1.7(16.2) \mathrm{cm}$ & $17.1 \pm 2(17.1) \mathrm{cm}$ \\
& Right & $18 \pm 1.5(17.6) \mathrm{cm}$ & $16.2 \pm 1.7(15.9) \mathrm{cm}$ & $16.9 \pm 1.8(17) \mathrm{cm}$ \\
Volume & Left & $2738 \pm 533(2817) \mathrm{cm}^{3}$ & $1968 \pm 505(2028) \mathrm{cm}^{3}$ & $2301 \pm 636(2262) \mathrm{cm}^{3}$ \\
& Right & $3121 \pm 605(3226) \mathrm{cm}^{3}$ & $2300 \pm 547(2332) \mathrm{cm}^{3}$ & $2663 \pm 667(2583) \mathrm{cm}^{3}$ \\
\hline
\end{tabular}


The phantom is made of silicon material, fiberglass, color pigment, and plastic mold. Elasticity of silicon is good for lung phantom to inflate and deflate. As this research needs conductive surface to impose inductance, additional thin copper sheet envelope is also assembled. Figure 3 shows lung phantom design along with its physical laboratory prototype.
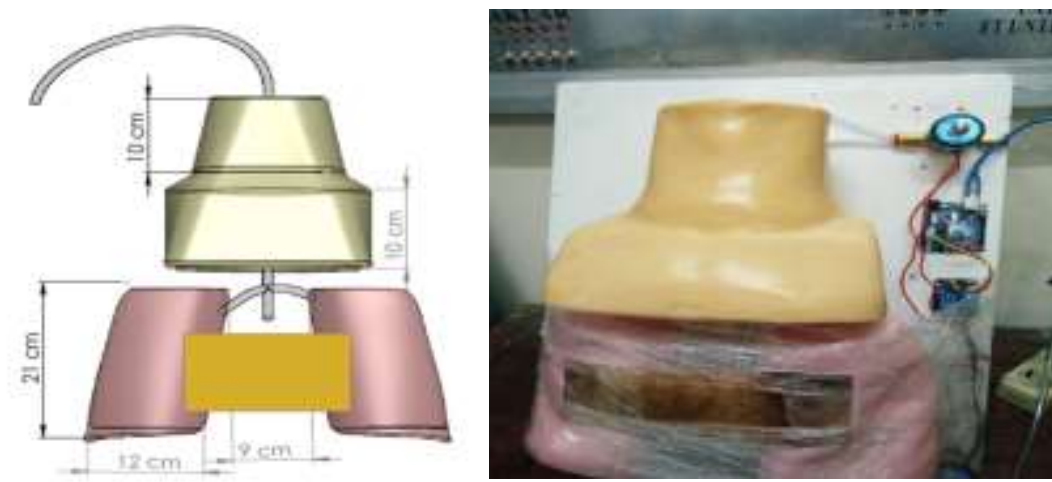

Figure 3. Lung phantom design and prototype

\section{MONITORING RESULTS AND ANALYSIS}

Experiment was set involving oxygen tube (air supply), solenoid valve (controlled gate), relay, Arduino Uno (controller electronics), and lung phantom (as shown in Figure 4). Programming on microcontroller was composed for setting solenoid valve channeling oxygen tube and lung phantom. Initially, both of solenoid valves are closed for 3 seconds. Then, solenoid valve on oxygen tube will open for 2 seconds; while on lung phantom is still closed. After 2 seconds, solenoid valve on oxygen tube will close for 2 seconds and on lung phantom is opened. Then, both of solenoid valves will close again for 1 second. These operations are maintained during experiment.

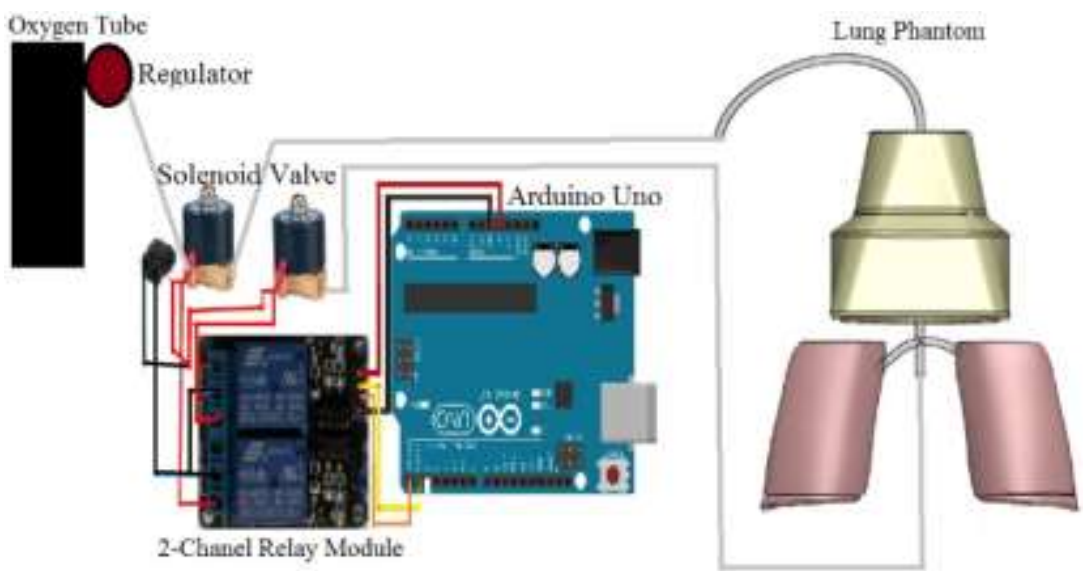

Figure 4. Hardware assembly

Monitoring system incorporates magnetic sensor LDC1000 connected into laptop port. Lung phantom can inflate and deflate automatically like human's respiration pattern. Magnetic sensor will read inductance value and proximity of lung phantom. The result will be shown on LDC1000 EVM GUI. Figure 5 shows the setup of monitoring system. 


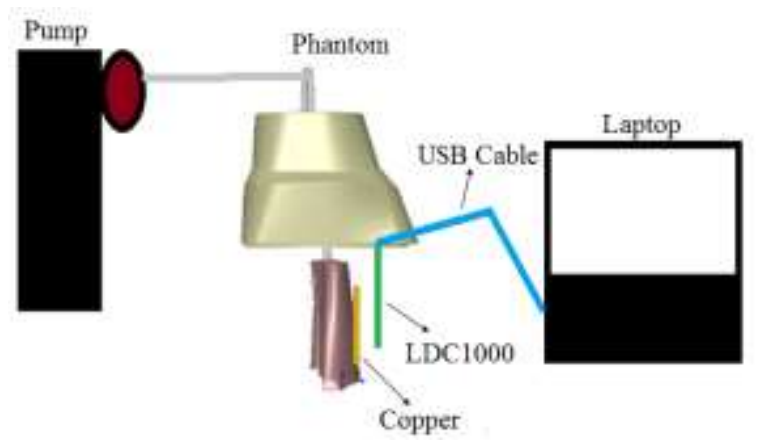

Figure 5. Monitoring system setup

Inductance value in relationship with proximity between sensor and phantom's surface was observed. Distance was ranged from 0 to $10 \mathrm{~mm}$ incurring linear increase and decrease of inductance when lung phantom is deflating and inflating respectively. Figure 6 plots graphs of the mechanism.

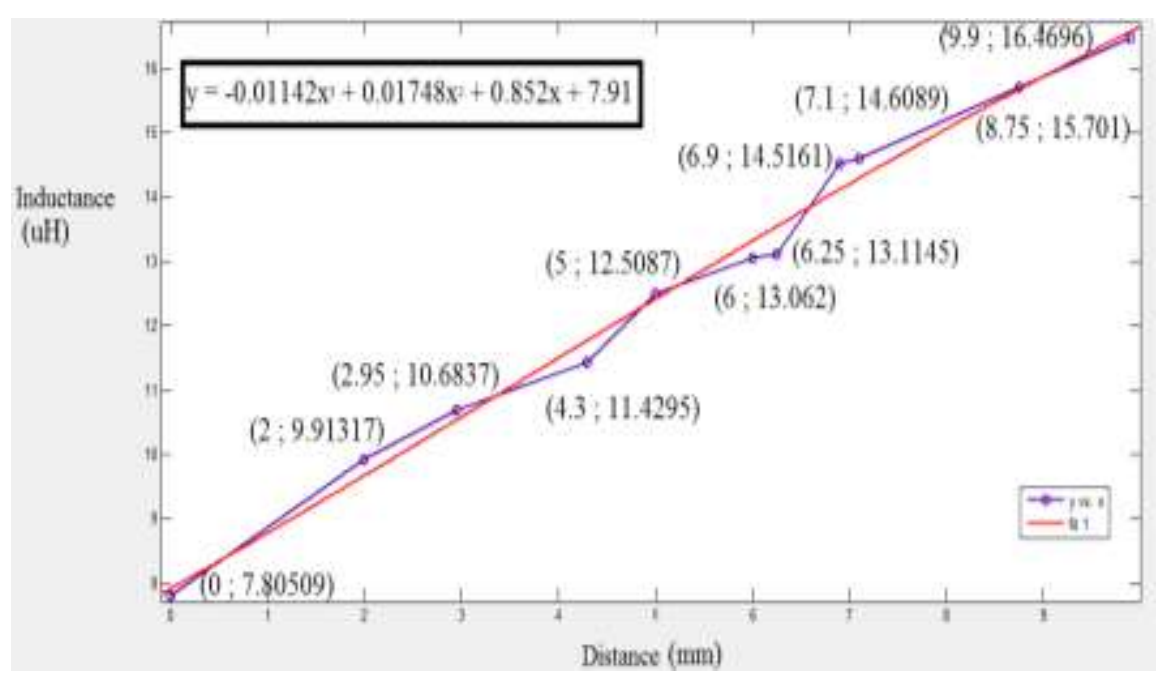

(a)

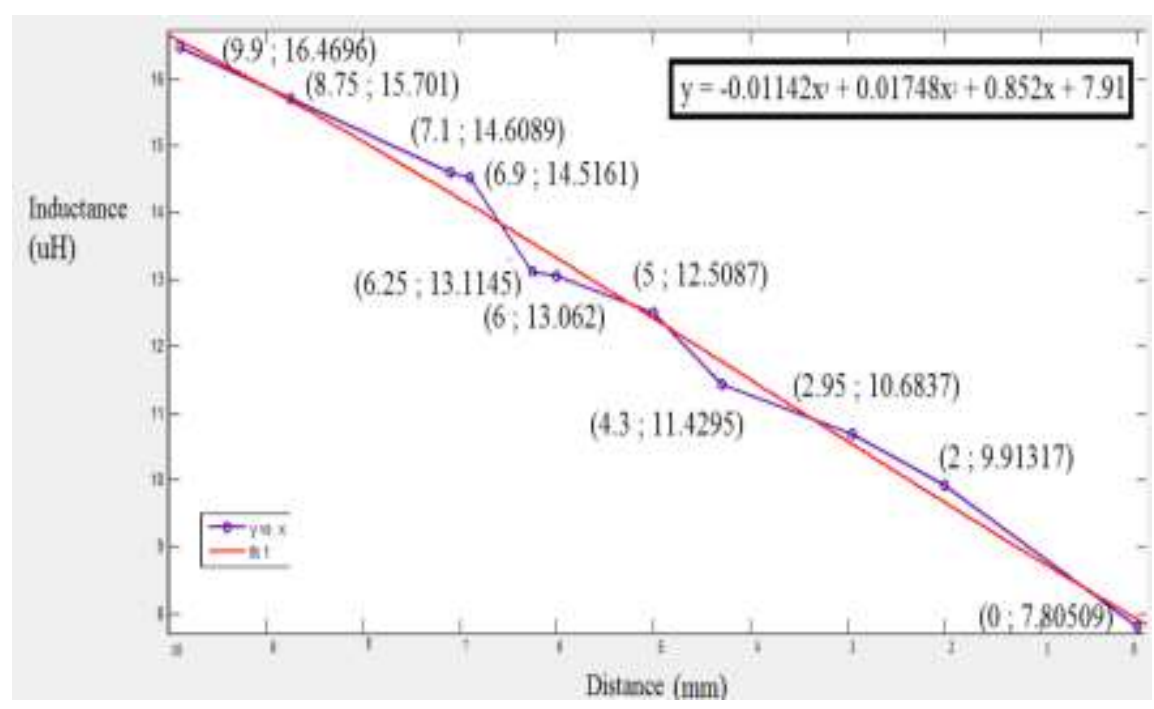

(b)

Figure 6. Inductance vs distance lung phantom is deflating (a) and inflating (b) 
Normal respiration static data which contains inspiration and expiration (with stop) was compiled to produce inductance graph in Figure 7. Note that horizontal axis (distance in $\mathrm{mm}$ ) is arranged reverse mirrored so that the pattern can be obviously seen. For continuous monitoring in real-time operation, LDC1000 EVM GUI was used providing proximity and inductance data as captured in Figure 8.

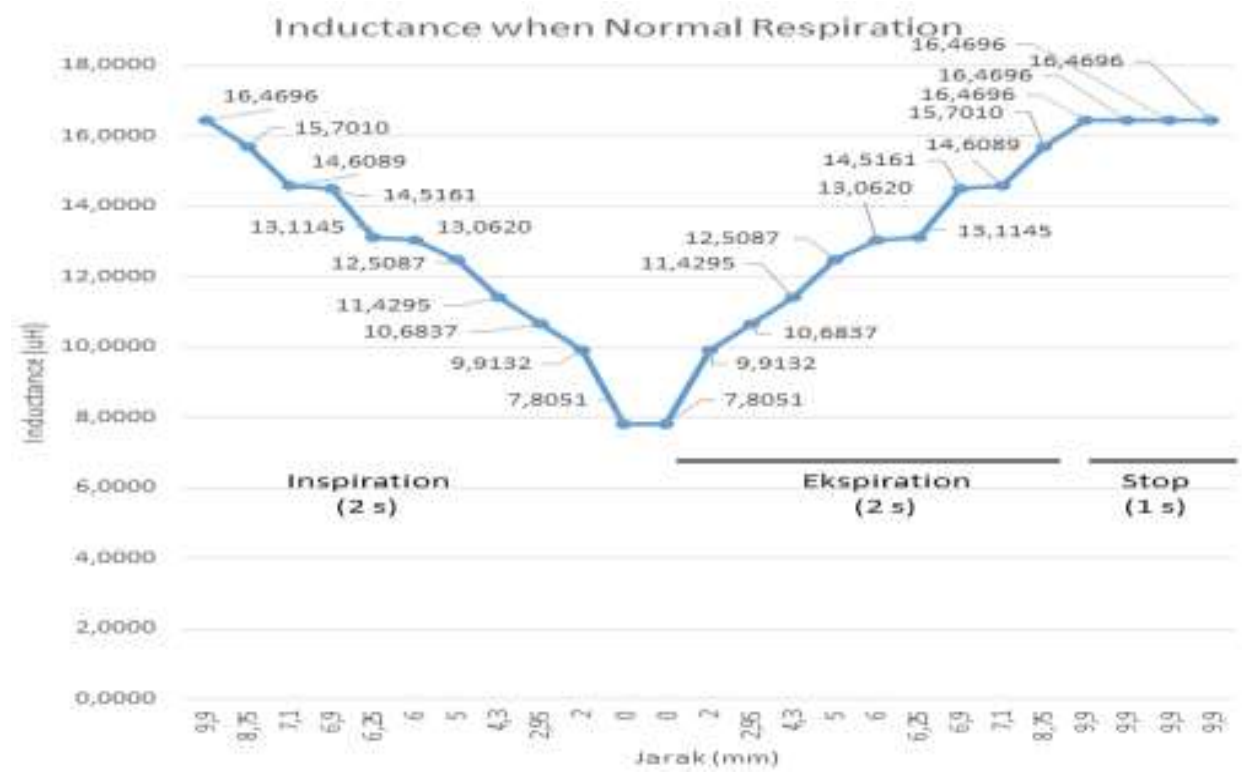

Figure 7. Lung Phantom static data of normal respiration

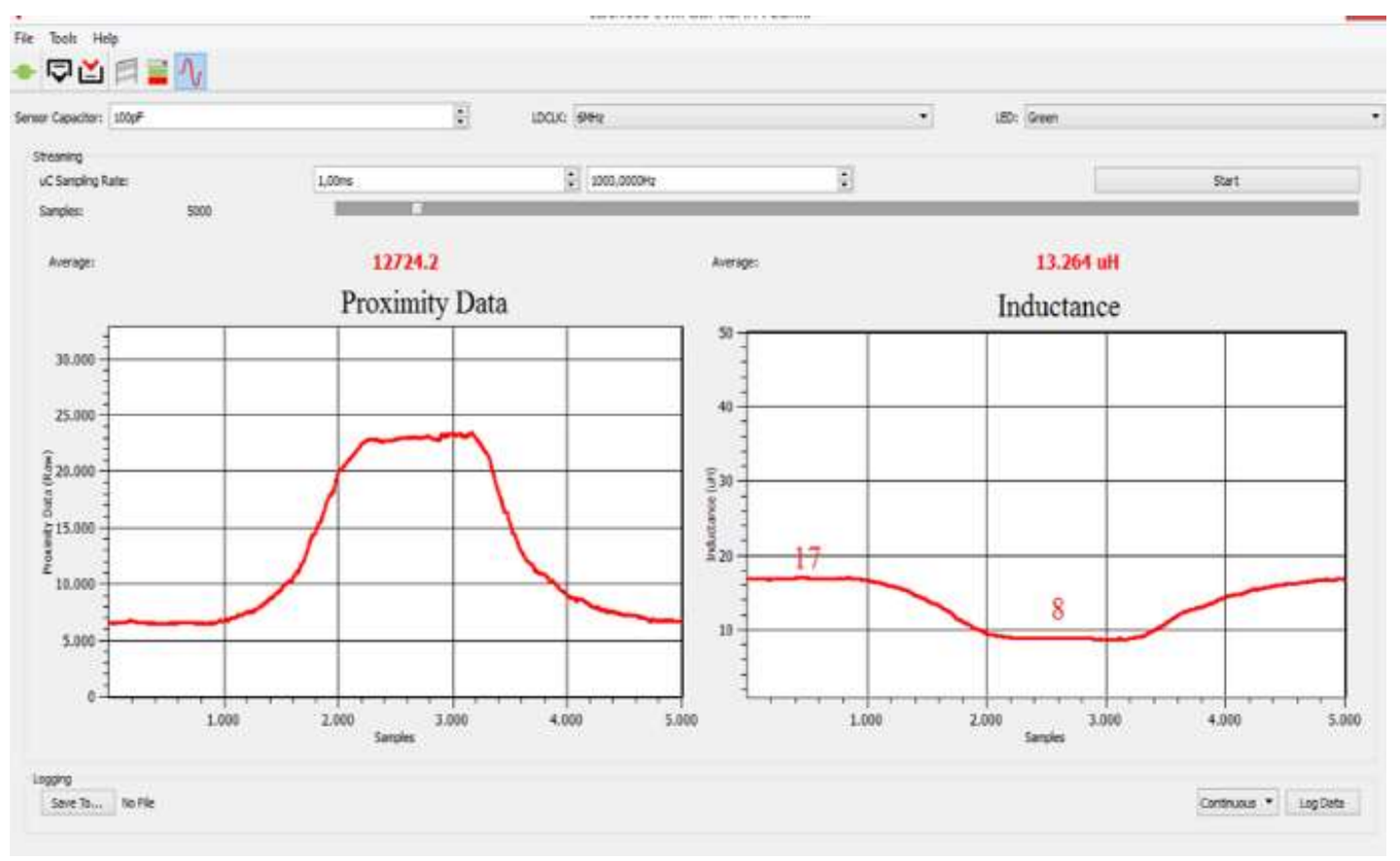

Figure 8. Continuous proximity and inductance monitoring via GUI

The LDC1000 is a sensitive sensor; hence small distance change will affect the result. Air flow was also set to the time of real lung when inflate and deflate, i.e.: two seconds for inspiration and expiration, whereas one second for stop. Comparison between static (manual) and continuous real-time (auto) inductance values at respiration stages is described in Table 2. 
Table 2. Comparison Continuous vs Static Experiment

\begin{tabular}{lcc}
\hline \multicolumn{1}{c}{ Stage } & Continous $(\mathrm{uH})$ & Static $(\mathrm{uH})$ \\
\hline Inspiration & 8 & 7.805094 \\
Ekspiration & 17 & 16.469637 \\
Stop & 17 & 16.469637 \\
\hline
\end{tabular}

There is difference of inductance level between continuous and static experiment. In continuous auto mode, the volume of air supplied into lung phantom is different from the volume of air involved in the real human respiration. This is due to simplicity for demonstrating inflate and deflate of lung phantom. For static manual mode, the volume of air supplied into lung phantom is similar like the volume of air in the real human respiration.

\section{CONCLUSION}

Prototype for laboratory scale respiration monitoring on lung phantom using magnetic sensor has been assembled and tested. Inductance values related to proximity between lung phantom surface and sensor are in proportion to inflate and deflate mechanism in respiration process. Further research could be done in manipulating abnormal respiration pattern for case study of various lung diseases. The results will be referred for vital signs telemonitoring system design based on contactless and portable devices.

\section{ACKNOWLEDGEMENT}

Authors would like to thank members of Medical Electronics Research Laboratory (MERC), Department of Electrical Engineering, UNTIRTA, for their valuable supports to this work.

\section{REFERENCES}

[1] Sulaiman NH, Samsuri NA, Rahim MKA, Seman FC, Inam M. Design and Analysis of Optimum Performance Pacemaker Telemetry Antenna. Telkomnika (Telecommunication Computing Electronics and Control). 2017; 15(2): 877-882.

[2] Jeong JW, Jang YW, Lee I, Shin S, Kim S. Wearable respiratory rate monitoring using piezo-resistive fabric sensor. World congress on medical physics and biomedical engineering. Berlin. 2009: 282-284.

[3] Padasdao B, Boric-Lubecke O. Respiratory rate detection using a wearable electromagnetic generator. Annual International Conference of the IEEE Engineering in Medicine and Biology Society. 2011: 3217-3220.

[4] Bagchi S, Chattopadhyay M. Real-time monitoring of respiratory diseases of distantly located elderly impaired patients. Sensing Technology: Current Status and Future Trends I. 2014: 25-40.

[5] Liu JJ, Huang MC, Xu W, Zhang X, Stevens L, Alshurafa N, Sarrafzadeh M. Breathsens: A continuous on-bed respiratory monitoring system with torso localization using an unobtrusive pressure sensing array. IEEE journal of biomedical and health informatics. 2015; 19(5): 1682-1688.

[6] Ojarand J, Pille S, Min M, Land R, Oleitšuk J. Magnetic induction sensor for the respiration monitoring. In Proc. of 10th Int. Conf. on Bioelectromagnetism (icBEM). Tallinn. 2015: 1-4.

[7] Muttakin I, Yeap SY, Mansor MM, Fathil MH, Ibrahim I, Ariffin I, Supriyanto E. Low cost design of precision medical ultrasound power measurement system. International Journal of Circuits, Systems and Signal Processing. 2011; 5(6): 672-682.

[8] LDC1000 Inductance to Digital Converter. Texas Instrument. Datasheet SNOSCX2A. 2013.

[9] Oberhauser C. LDC Target Design. Texas Instrument. Application note SNOA957A. 2016.

[10] Benabdellah A, Abbassi Z, Nakheli A. New Electromagnetic Force-Displacement Sensor. Bulletin of Electrical Engineering and Informatics (BEEI). 2016; 5(3): 334-339.

[11] Kramer GH, Capello K, Bearrs B, Lauzon A, Normandeau L. Linear dimensions and volumes of human lungs obtained from ct images. Health physics. 2012; 102(4): 378-383. 